\title{
Effect of etching the coronal dentin with the rubbing technique on the microtensile bond strength of a universal adhesive system
}

\section{Wpływ wytrawiania zębiny koronowej techniką wcierania na mikrorozciągliwą siłę wiązania uniwersalnego systemu adhezyjnego}

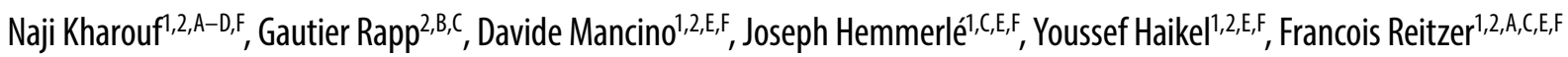 \\ 1 Inserm UMR_S 1121, Biomaterials and Bioengineering, University of Strasbourg, France \\ ${ }^{2}$ Department of Conservative Dentistry and Endodontics, Faculty of Dental Medicine, University of Strasbourg, France \\ A - research concept and design; $\mathrm{B}$ - collection and/or assembly of data; $\mathrm{C}$ - data analysis and interpretation; \\ $\mathrm{D}$ - writing the article; $\mathrm{E}$ - critical revision of the article; $\mathrm{F}$ - final approval of the article
}

\begin{abstract}
Address for correspondence
Naji Kharouf

E-mail: dentistenajikharouf@gmail.com
\end{abstract}

Funding sources

None declared

Conflict of interest

None declared

Received on June 13, 2019

Reviewed on July 21,2019

Accepted on August 10, 2019

Published online on December 3, 2019

Cite as

Kharouf N, Rapp G, Mancino D, Hemmerlé J, Haikel Y, Reitzer F. Effect of etching the coronal dentin with the rubbing technique on the microtensile bond strength of a universal adhesive system. Dent Med Probl. 2019;56(4):343-348.

doi:10.17219/dmp/111697

DOI

10.17219/dmp/111697

Copyright

๑ 2019 by Wroclaw Medical University

This is an article distributed under the terms of the

Creative Commons Attribution 3.0 Unported License (CC BY 3.0)

(https://creativecommons.org/licenses/by/3.0/)

\begin{abstract}
Background. The adhesion of composite resins to the dentin substrate is influenced by the treatment of the smear layer. While etch-and-rinse systems require dentin to be conditioned with phosphoric acid, self-etching systems preserve the smear layer by incorporating it into the adhesive layer.

Objectives. The objective of this study was to evaluate the influence of etching with the rubbing technique on the microtensile bond strength ( $\mu \mathrm{TBS}$ ) of a universal adhesive to dentin.

Material and methods. Eighteen extracted teeth were selected. Two etch-and-rinse techniques (with and without rubbing) and a self-etching technique were used to bond the dentin surfaces with a universal adhesive system. After $24 \mathrm{~h}$, the bonded samples were prepared for the $\mu \mathrm{TBS}$ testing. The specimens were loaded with a tensile force at a crosshead speed of $0.5 \mathrm{~mm} / \mathrm{min}$ until failure. The scanning electron microscope (SEM) analyses were used to reveal the failure modes. The data were statistically analyzed with the one-way analysis of variance (ANOVA) and $x^{2}$ tests.

Results. The etch-and-rinse system with rubbing produced significantly lower bond strength $\left(42.11 \pm 9.26 \mathrm{MPa}_{2}\right)$ than the etch-and-rinse system without rubbing $(47.30 \pm 8.12 \mathrm{MPa})$ and significantly higher bond strength than the self-etching system (38.07 $\pm 9.49 \mathrm{MPa})$.

Conclusions. Under the conditions of this study, dentin etched with phosphoric acid for $3 \mathrm{~s}$ in the etchand-rinse mode with the rubbing technique for a universal adhesive system decreases the $\mu \mathrm{TBS}$ of the composite to dentin.
\end{abstract}

Key words: etching, phosphoric acid, universal adhesive, rubbing technique

Słowa kluczowe: wytrawianie, kwas fosforowy, uniwersalny materiał adhezyjny, technika wcierania 


\section{Introduction}

Dentin is capped by a crown made of highly mineralized and protective enamel. ${ }^{1}$ The composition and structure of the enamel and dentin matrices are different, so the adhesion mechanisms for these tissues are also dissimilar. ${ }^{2}$ Bonding to dentin has been considered more difficult treatment because of the complex histology and composition of dentin. ${ }^{3}$ A universal system has been described as ideally a single-bottle one, which can be used in the total-etching, self-etching and selective-etching modes. ${ }^{4}$ Bonding to dentin with total-etch adhesives is accomplished in 2 steps. The $1^{\text {st }}$ step is to etch the surface by applying a strong acid, and the $2^{\text {nd }}$ step is the penetration and then polymerization of the resin in situ inside the etched surface. ${ }^{5}$ On the other hand, self-etch adhesives do not require a separate etching step, as they contain acidic monomers. ${ }^{6}$ Etching dentin with phosphoric acid for $15 \mathrm{~s}$ removes almost all mineral content, exposes collagen fibers and allows them to be infiltrated with the adhesive material. ${ }^{7}$ In the self-etching mode, a universal adhesive partially dissolves the smear layer without demineralizing the tooth surface too profoundly, thereby removing hydroxyapatite at the interface. Preserving hydroxyapatite at the interface provides calcium for chemical bonding to the functional monomer. ${ }^{6}$ Selective dentin etching is a relatively new approach used to improve resin-dentin bonding by preserving hydroxyapatite crystals inside the intrafibrillar collagen spaces. ${ }^{8,9}$ Universal adhesives used in the self-etching mode produce superior, longterm dentin bonding compared to the etch-and-rinse $\operatorname{method}^{10,11}$; reducing the etching time may be useful for achieving complete penetration and for sealing the dentin surface. ${ }^{12}$ Selective etching for $3 \mathrm{~s}$ using $37 \%$ phosphoric acid improves the effectiveness of dentin bonding. ${ }^{13}$ Phosphoric acid is the most suitable acid conditioner in dental restoration. $^{14}$

Hanabusa et al., who compared the self-etching mode with 'dry-bonding' and 'wet-bonding' etch-and-rinse techniques, noted that the self-etching approach was preferred on the dentin surface. ${ }^{15}$ Zecin-Deren et al. recommended using triple adhesive layers with simplified adhesive systems in order to improve their performance. ${ }^{16}$

The present study highlights another application protocol, and discusses the rubbing action of phosphoric acid in the etch-and-rinse technique on the dentin surface before the rinsing and bonding procedures.
The bond strength measurement is one of the most effective methods for characterizing commercial dentin bonding products. ${ }^{17,18}$

The purpose of this in vitro study was to evaluate and compare the microtensile bond strength ( $\mu \mathrm{TBS}$ ) of 2 different etch-and-rinse protocols and a self-etching protocol for universal adhesive systems. The null hypothesis was that there are no differences in the $\mu$ TBS of a dentin bond after the bonding procedure between the 3 different etching techniques.

\section{Material and methods}

\section{Specimen preparation}

This study was revised and approved by the Ethics Committee of the Faculty of Dental Medicine at the University of Strasbourg and Strasbourg University Hospital, France (protocol No. 201905).

In total, 18 recently extracted caries-free human mandibular molars were selected. The teeth were washed with physiological serum and stored in $70 \%$ ethanol for 2 weeks at $4^{\circ} \mathrm{C}$. We divided the extracted teeth into 3 groups. The dentin bonding sites were prepared by sectioning the teeth and removing the root structure.

One section was made perpendicular to the longitudinal axis of the tooth crown to obtain a single coronal dentin wafer, $4 \mathrm{~mm}$ in thickness, then polished with P320-grit silicon carbide paper (Escil, Chassieu, France) for $60 \mathrm{~s}$ under water cooling conditions to get the same surface as in the case of using a dental diamond burr drill. ${ }^{13}$

The $1^{\text {st }}$ group (G1) consisted of 6 teeth which were bonded in the self-etching mode using a universal adhesive (Prime \& Bond ${ }^{\circledR}$ active - P\&Ba; Dentsply DeTrey $\mathrm{GmbH}$, Konstanz, Germany) (Table 1). The $2^{\text {nd }}$ group (G2) consisted of 6 teeth which were bonded using the same universal adhesive in the etch-and-rinse mode - etching with $37 \%$ phosphoric acid (Itena Clinical, Villepinte, France) for $3 \mathrm{~s}$, followed by rinsing with water for $30 \mathrm{~s} .{ }^{13}$ The $3^{\text {rd }}$ group (G3) consisted of 6 teeth which were bonded in the etch-and-rinse mode with the rubbing technique - etching with $37 \%$ phosphoric acid for $3 \mathrm{~s}$ with the rubbing method using a microbrush, and then rinsing with water for $30 \mathrm{~s}$. The adhesive was applied according to the manufacturer's

Table 1. Chemical composition of and instructions for the material used

\begin{tabular}{|c|c|c|c|}
\hline Material and manufacturer & Composition & $\mathrm{pH}$ & Instructions for use \\
\hline $\begin{array}{l}\text { Prime \& Bond Active (P\&Ba); } \\
\text { Dentsply DeTrey GmbH, } \\
\text { Konstanz, Germany }\end{array}$ & $\begin{array}{l}\text { - bisacrylamide } 1 \text { (25-50\%) } \\
\text { - 10-methacryloxydecyl dihydrogen phosphate (10-MDP) (10-25\%) } \\
\text { - bisacrylamide } 2 \text { (2.5-10\%) } \\
\text { - 4-(dimethylamino)benzonitrile (0.1-1\%) } \\
\text { - dipentaerythritol pentaacrylate phosphate (PENTA), propan-2-ol (10-25\%) } \\
\text { - water (20\%) }\end{array}$ & 2.5 & $\begin{array}{l}\text { apply adhesive, } \\
\text { slight agitation (20 s), } \\
\text { mild air-blowing (5 s), } \\
\text { light-curing (20 s) }\end{array}$ \\
\hline
\end{tabular}


protocol (brushing for $20 \mathrm{~s}$, air-drying for $5 \mathrm{~s}$ and lightcuring for $20 \mathrm{~s}$ ). The adhesive was light-cured for $20 \mathrm{~s}$ with the aid of an Optilux ${ }^{\circledR} 501$ apparatus (Kerr Dental France, Ivry-sur-Seine, France) at a light intensity of $600 \mathrm{~mW} / \mathrm{cm}^{2}$.

\section{Microtensile bond strength}

The samples from each group were prepared for the $\mu$ TBS tests. Resin composite build-ups were performed using a resin composite $\left(\right.$ Ceram $^{\circledR} \mathrm{X}$; Dentsply Sirona) in 3 increments of $2 \mathrm{~mm}$ each. Each increment was light-cured for $40 \mathrm{~s}$, according to the manufacturer's instructions, until a height of $6 \mathrm{~mm}$ was reached. The teeth were stored in distilled water in an incubator for $24 \mathrm{~h}$ at $37^{\circ} \mathrm{C}$. This experimental study was carried out in accordance with the International Standards Organization's ISO TR 11405. The samples were longitudinally sectioned using a diamond wire saw (WELL Diamond Wire Saws SA, Le Locle, Switzerland) in both $\mathrm{X}$ - and Y-axes with a cross-sectional area of approx. $1 \mathrm{~mm}^{2}$. The sticks (9-12 from each sample) were kept moist until testing. For the $\mu$ TBS tests, the specimens were attached to a testing machine (Instron ${ }^{\circledR} 3345$; Instron, Norwood, USA) with a cyanoacrylate adhesive. The specimens were loaded with a tensile force at a crosshead speed of $0.5 \mathrm{~mm} / \mathrm{min}$ until failure. The microtensile bond strength $[\mathrm{MPa}]$ was calculated by dividing the load at failure $[\mathrm{N}]$ by the bonded surface area $\left[\mathrm{mm}^{2}\right]$.

\section{Scanning electron microscope preparations and observations}

After the $\mu$ TBS testing process, the dentin sides of all samples were dehydrated in a graded ethanol series. The samples were sputter-coated with gold-palladium alloys (20/80) using a Hummer ${ }^{\circledR}$ JR sputtering device (Technics, San Francisco, USA). Later on, a Quanta ${ }^{\circledR} 250$ FEG scanning electron microscope (SEM) (FEI Company, Eindhoven, the Netherlands) functioning with an accelerating voltage of $10 \mathrm{kV}$ was used for the observation of all coated specimens (61 samples from G1, 60 samples from G2 and 60 samples from G3).

The dentin surfaces were examined under SEM at $\times 100$ magnification in order to determine the mode of failure. The failure modes were categorized into the following 3 types $^{19}$ :

- type 1: adhesive failure;

- type 2: cohesive failure in the composite or dentin; and

- type 3: mixed failure, in the case when one area exhibited cohesive failure while other areas exhibited an adhesive fracture.

\section{Statistical analysis}

Any samples that exhibited cohesive or mixed failures were excluded from the statistical analysis. ${ }^{20,21}$ The data analysis was performed with SigmaPlot, v. 11.2 (Systat Software Inc., San Jose, USA). The one-way analysis of variance (ANOVA) test was applied in the comparisons of the $\mu$ TBS data of the 3 groups. The $X^{2}$ test was performed to compare the effects of the 3 different etching protocols used on the mode of failure. In all tests, a statistical significance level of $\alpha=0.05$ was adopted.

\section{Results}

\section{Microtensile bond strength test}

A total of 181 specimens (sticks) were available for the $\mu$ TBS testing. The mean values of $\mu$ TBS with standard deviations (SDs) are shown in Table 2. The ANOVA test revealed a statistically significant difference between the means corresponding to the different etching techniques. In a pairwise comparison for the pair $(G 1, G 2)$, the test resulted in $p<0.001$, and for the pairs $(\mathrm{G} 2, \mathrm{G} 3)$ and $(\mathrm{G} 1, \mathrm{G} 3)$, $p=0.034$ and $p=0.05$, respectively. Therefore, the null hypothesis was rejected $(p<\alpha)$.

Table 2. Descriptive statistics of the microtensile bond strength ( $\mu$ TBS) of a dentin bond in adhesive failure samples

\begin{tabular}{|c|c|c|c|c|}
$\begin{array}{l}\text { Experimental } \\
\text { group }\end{array}$ & $\begin{array}{c}\mathrm{N} \\
\text { (total) }\end{array}$ & $\begin{array}{c}\mathrm{n} \\
\text { (cohesive and } \\
\text { mixed failures) }\end{array}$ & $\begin{array}{c}\mathrm{n} \\
\text { (adhesive } \\
\text { failures) }\end{array}$ & $\begin{array}{c}\mu \mathrm{TBS} \\
\text { mean } \pm \text { SD } \\
{[\mathrm{MPa}]}\end{array}$ \\
\hline G1 & 61 & 19 & 42 & $38.07 \pm 9.49$ \\
G2 & 60 & 26 & 34 & $47.30 \pm 8.12$ \\
G3 & 60 & 23 & 37 & $42.11 \pm 9.26$ \\
\hline
\end{tabular}

SD - standard deviation

\section{Scanning electron microscope failure analysis}

The dentin side of each stick was observed in order to identify the failure type. Higher $\mu$ TBS values were mostly associated with a higher tendency toward cohesive failure in the composite (Fig. 1A) or mixed failure (Fig. 1B,C), in particular for G2 and G3. Most of the self-etching samples (G1) revealed adhesive interfacial failure (Fig. 1D). The interaction between the groups and the failure modes indicated a non-statistically significant correlation $(p>0.001)$. The etch-and-rinse mode interfaces (G2, G3) often presented with intra-tubule tags as well (Fig. 2), particularly when the adhesive was applied in the etch-andrinse mode without the rubbing technique (G2). 

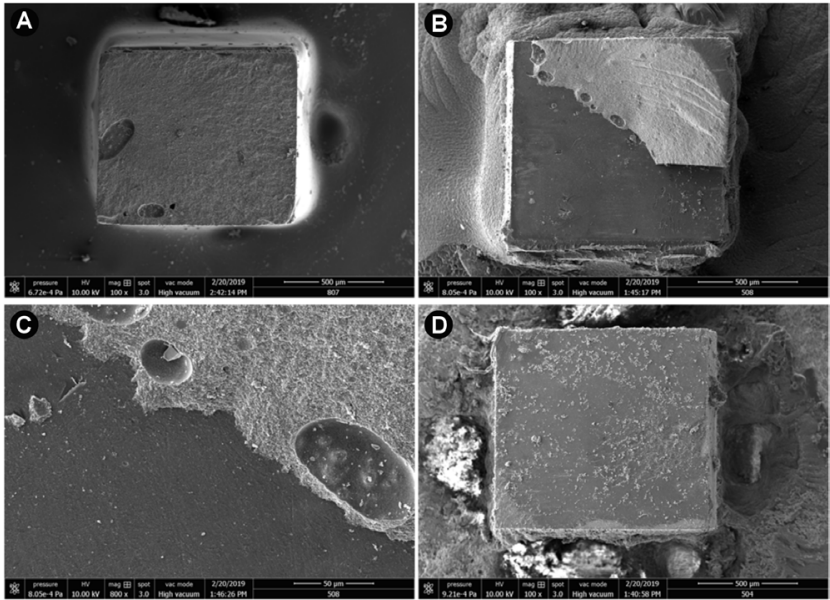

Fig. 1. A - scanning electron microscope (SEM) failure analysis of cohesive failure in the composite ( $\times 100$ magnification); B - SEM photomicrograph of mixed interfacial failure between the adhesive and composite layers (×100 magnification); C - higher magnification of mixed failure showing the interface between the adhesive and composite layers (×800 magnification); D - representative SEM photomicrograph of adhesive failure ( $\times 100$ magnification)

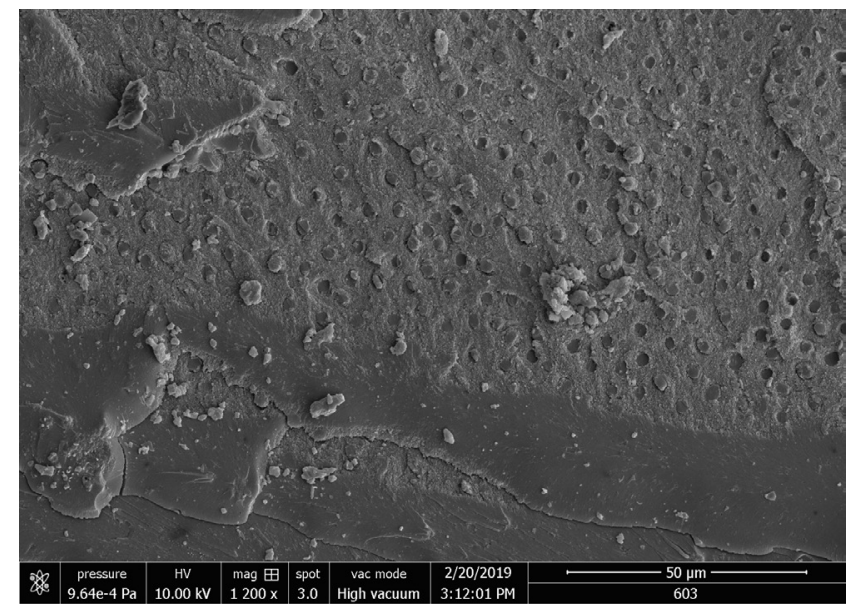

Fig. 2. Scanning electron microscope (SEM) image of the dentin-adhesive interface in bonded dentin using a universal adhesive in the etch-and-rinse mode without the rubbing technique (G2), showing the uniform and complete filling of dentinal tubules ( $\times 1,200$ magnification)

\section{Discussion}

This study presents an investigation of the effects of etching with the rubbing technique on the resin-dentin interface. The tooth preparation processes bring important changes in the dentin thickness and density, leading to different resin bonding results. ${ }^{22}$ In an attempt to improve the quality of the resin-dentin interface, some studies suggest specific clinical procedures, such as applying multiple adhesive coats, prolonging the exposure time during light-curing, using warm air to evaporate the solvent, and rubbing the adhesive onto the tooth surfaces. ${ }^{23}$ Concerning the etch-and-rinse protocol (G2), it would appear that it is necessary to etch the dentin surface for $3 \mathrm{~s}$ before the bonding of a universal adhesive. Similar results were obtained by Stape et al., who noted that the use of phosphoric acid for $3 \mathrm{~s}$ improves immediate and longterm resin-dentin bonding without overexposing demineralized collagen. ${ }^{13}$

In our study, the rubbing technique was proposed during etching in order to improve bonding quality. Under the experimental conditions defined in this in vitro study, the rubbing action (G3) does not enhance $\mu$ TBS to dentin; on the contrary, this protocol statistically decreases $\mu \mathrm{TBS}$.

The SEM images from the present study show that etching by means of phosphoric acid with or without the rubbing technique for $3 \mathrm{~s}$ before bonding removes the smear plugs, better opens up tubules which occur in the presence of resin tags (Fig. 2) and provides the micromechanical interlocking of the adhesive resin. It is generally accepted that the primary critical factor in determining an adequate bond is the micromechanical interlocking of the adhesive resin in the demineralized tooth surface. ${ }^{24}$ Bahillo et al., in their use of an acidic monomer (glycerol phosphate dimethacrylate - GPDM), noted that selective dentin etching with phosphotic acid did not significantly improve marginal adaptation, indicating a self-etching effect most probably due to the presence of GPDM in the composition of the OptiBond ${ }^{\mathrm{TM}}$ FL primer. ${ }^{25}$ There is still a point of discussion concerning the etching time. Etching dentin for $3 \mathrm{~s}$ in the case of a complex cavity is very difficult to translate into clinical application, because it is too easy to exceed this time, especially with rubbing.

The statistical analyses in our study revealed that etching associated with the rubbing technique decreased $\mu$ TBS (Table 2). Phosphoric acid demineralized dentin and exposed the collagen matrix, containing hydroxyapatite. ${ }^{26}$ Our hypothesis was that the rubbing action at the time of etching the dentin surface could crush and destroy collagen fibers and hydroxyapatite crystals. Hashimoto et al. noted that excessive acid-conditioning caused deeper demineralization of both intertubular and peritubular dentin, which in turn meant that the 2 kinds of dentin were not capable of being entirely infiltrated by resin monomers, leading to decreased bond strength. ${ }^{27}$ Van Meerbeek et al. highlight the importance of keeping hydroxyapatite around collagen in order to better protect collagen against hydrolysis, and thus early degradation of the bond. ${ }^{28}$ Therefore, functional monomers containing acidic groups cannot interact with hydroxyapatite. A functional monomer such as 10-methacryloxydecyl dihydrogen phosphate (10-MDP) can form stable calciumphosphate complexes and self-assemble into the form of a regular layered structure at the apatite surface. ${ }^{29-31}$ Preserving calcium at the bonded interface, in theory, could favor this peculiar chemical bonding process. Wang and Spencer noted that agitating acid gel facilitated etching and penetration into dentin, but it is not recommended, especially for longer etching times. ${ }^{32}$

The $\mu$ TBS test is considered the most reliable technique for assessing the real strength of the interfacial bond between an adhesive material and a tooth. ${ }^{31}$ One of the many 
advantages of this test is that it can reveal the adhesive failure type and result in fewer cohesive and mixed failures. ${ }^{33}$ Cohesive and mixed failures where observed more often when the $\mu$ TBS values increased, which might be explained by the good mechanical properties of a bond, associated with the particular bonding technique used. In contrast, cohesive failures in the composite may have been caused by errors made during the build-up of the composite layers. The results in Table 2 present the incidence of each failure mode induced by particular etching techniques. The present study noted a higher tendency toward cohesive or mixed failure associated with higher $\mu$ TBS values, but these results are not significantly different (the $\chi^{2}$ test; $p>0.001$ ). In $\mathrm{G} 1$, bonding was weaker than in the specimens prepared with the etch-and-rinse mode, the most common failure type was adhesive fracture and minimal resin penetration occurred. Takamizawa et al. noted that using the etch-and-rinse mode for universal adhesives did not decrease dentin bond quality. ${ }^{34}$

The present in vitro study has some limitations. It did not address the effect of the rubbing action on dentin sensitivity, which should be followed with clinical studies. The relatively short period of water storage $(24 \mathrm{~h})$ was another limitation. Furthermore, dentin bonding by means of the etch-and-rinse method has been claimed to be technique-sensitive. ${ }^{32}$

\section{Conclusions}

Etching with $37 \%$ phosphoric acid for $3 \mathrm{~s}$ without the rubbing technique is recommended before applying a universal adhesive on the dentin surface in order to improve bond strength.

\section{ORCID iDs}

Naji Kharouf (1) https://orcid.org/0000-0001-6768-138X Gautier Rapp (1) https://orcid.org/0000-0002-0800-7827 Davide Mancino (1) https://orcid.org/0000-0001-7376-371X Joseph Hemmerlé (1) https://orcid.org/0000-0001-8483-857X Youssef Haikel (1) https://orcid.org/0000-0002-4469-0360 Francois Reitzer (1) https://orcid.org/0000-0002-7878-7136

\section{References}

1. Goldberg M, Kulkarni AB, Young M, Boskey A. Dentin: Structure, composition and mineralization. Front Biosci (Elite Ed). 2011;3:711-735.

2. Pashley DH, Sano H, Ciucchi B, Yoshiyama M, Carvalho RM. Adhesion testing of dentin bonding agents: A review. Dent Mater. 1995;11(2):117-125.

3. Brännström M, Glantz PO, Nordenvall KJ. The effect of some cleaning solutions on the morphology of dentin prepared in different ways: An in-vivo study. ASDC J Dent Child. 1979;46(4):291-295.

4. Ikeda T, De Munck J, Shirai K, et al. Effect of air-drying and solvent evaporation on the strength of HEMA-rich versus HEMA-free onestep adhesives. Dent Mater. 2008;24(10):1316-1323.

5. Grégoire G, Ahmed Y. Evaluation of the enamel etching capacity of six contemporary self-etching adhesives. J Dent. 2007;35(5):388-397.

6. Van Meerbeek B, Yoshihara K, Yoshida Y, Mine A, De Munck J, Van Landuyt KL. State of the art of self-etch adhesives. Dent Mater. 2011;27(1):17-28.
7. Pashley DH, Tay FR, Breschi L, et al. State of the art etch-and-rinse adhesives. Dent Mater. 2011;27(1):1-16.

8. Li B, Zhu X, Ma L, et al. Selective demineralisation of dentine extrafibrillar minerals - a potential method to eliminate water-wet bonding in the etch-and-rinse technique. J Dent. 2016;52:55-62.

9. Bertassoni LE, Orgel JPR, Antipova O, Swain MV. The dentin organic matrix - limitations of restorative dentistry hidden on the nanometer scale. Acta Biomater. 2012;8(7):2419-2433.

10. Chen $\mathrm{C}$, Niu LN, Xie H, et al. Bonding of universal adhesives to dentine - Old wine in new bottles? J Dent. 2015;43(5):525-536.

11. Koshiro K, Inoue S, Tanaka T, et al. In vivo degradation of resin-dentin bonds produced by a self-etch vs. a total-etch adhesive system. Eur J Oral Sci. 2004;112(4):368-375.

12. Abu-Hanna A, Gordan VV, Mjor I. The effect of variation in etching times on dentin bonding. Gen Dent. 2004;52(1):28-33.

13. Stape THS, Wik P, Mutluay MM, Al-Ani AAS, Tezvergil-Mutluay A. Selective dentin etching: A potential method to improve bonding effectiveness of universal adhesives. J Mech Behav Biomed Mater. 2018;86:14-22.

14. Tezvergil-Mutluay A, Mutluay M, Seseogullari-Dirihan R, et al. Effect of phosphoric acid on the degradation of human dentin matrix. J Dent Res. 2013;92(1):87-91.

15. Hanabusa $M$, Mine $A$, Kuboki $T$, et al. Bonding effectiveness of a new 'multi-mode' adhesive to enamel and dentine. J Dent. 2012;40(6):475-484.

16. Zecin-Deren A, Sokolowski J, Szczesio-Wlodarczyk A, Piwonski I, Lukomska-Szymanska M, Lapinska B. Multi-layer application of self-etch and universal adhesives and the effect on dentin bond strength. Molecules. 2019;24(2).pii:E345.

17. Yeşilyurt C, Bulucu B. Bond strength of total-etch and self-etch dentin adhesive systems on peripheral and central dentinal tissue: A microtensile bond strength test. J Contemp Dent Pract. 2006;7(2):26-36.

18. Ozer $F$, Unlü N, Sengun A. Influence of dentinal regions on bond strengths of different adhesive systems. J Oral Rehabil. 2003;30(6):659-663.

19. Jang JH, Lee MG, Woo SU, Lee CO, Yi JK, Kim DS. Comparative study of the dentin bond strength of a new universal adhesive. Dent Mater J. 2016;35(4):606-612.

20. Wagner A, Wendler M, Petschelt A, Belli R, Lohbauer U. Bonding performance of universal adhesives in different etching modes. J Dent. 2014;42(7):800-807.

21. Scherrer SS, Cesar PF, Swain MV. Direct comparison of the bond strength results of the different test methods: A critical literature review. Dent Mater. 2010;26(2):e78-e93.

22 Sattabanasuk V, Vachiramon V, Qian F, Armstrong SR. Resin-dentin bond strength as related to different surface preparation methods. J Dent. 2007;35(6):467-475.

23. Reis A, Carrilho M, Breschi L, Loguercio AD. Overview of clinical alternatives to minimize the degradation of the resin-dentin bonds. Oper Dent. 2013;38(4):E1-E25.

24. Hashimoto $M$, Ohno $H$, Sano $H$, Kaga $M$, Oguchi $H$. In vitro degradation of resin-dentin bonds analyzed by microtensile bond test, scanning and transmission electron microscopy. Biomaterials. 2003;24(21):3795-3803.

25. Bahillo J, Roig M, Bortolotto T, Krejci I. Self-etching aspects of a threestep etch-and-rinse adhesive. Clin Oral Investig. 2013;17(8):1893-1900.

26. Perdigao J, Swift EJ. Analysis of dental adhesive systems using scanning electron microscopy. Int Dent J. 1994;44(4):349-359.

27. Hashimoto $M$, Ohno $H$, Kaga $M$, et al. Over-etching effects on micro-tensile bond strength and failure patterns for two dentin bonding systems. J Dent. 2002;30(2-3):99-105.

28. Van Meerbeek B, De Munck J, Yoshida Y, et al. Buonocore memorial lecture. Adhesion to enamel and dentin: Current status and future challenges. Oper Dent. 2003;28(3):215-235.

29. Van Landuyt KL, Yoshida Y, Hirata I, et al. Influence of the chemical structure of functional monomers on their adhesive performance. J Dent Res. 2008;87(8):757-761.

30. Yoshihara K, Yoshida Y, Nagaoka N, et al. Nano-controlled molecular interaction at adhesive interfaces for hard tissue reconstruction. Acta Biomater. 2010;6(9):3573-3582. 
31. Zhang Z, Wang X, Zhang L, et al. The contribution of chemical bonding to the short- and long-term enamel bond strengths. Dent Mater. 2013;29(7):e103-e112.

32. Wang $Y$, Spencer P. Effect of acid etching time and technique on interfacial characteristics of the adhesive-dentin bond using differential staining. Eur J Oral Sci. 2004;112(3):293-299.

33. Sadek FT, Goracci C, Cardoso PE, Tay FR, Ferrari M. Microtensile bond strength of current dentin adhesives measured immediately and 24 hours after application. J Adhes Dent. 2005;7(4):297-302.

34. Takamizawa T, Barkmeier WW, Tsujimoto A, et al. Influence of different etching modes on bond strength and fatigue strength to dentin using universal adhesive systems. Dent Mater. 2016;32(2):e9-e21. 